\title{
Amor y odio en la terminación del ejercicio profesional ${ }^{1}$
}

\author{
Sandra Buechler ${ }^{2}$ \\ New York, NY, USA
}

\begin{abstract}
Este trabajo presenta las elaboraciones de la autora sobre su experiencia y los sentimientos desplegados en torno a su decisión de retirarse del ejercicio profesional, tras cuarenta años de desempeñar su práctica como psicoterapeuta. Las ideas que en este trabajo se exponen, se complementan con las que se incluyen en el trabajo que sigue a continuación: "El Rey Lear y los desafíos de la jubilación".
\end{abstract}

Palabras clave: Amor, Odio, Jubilación, Psicoterapeuta.

This paper presents the author's elaborations on her experience and the feelings displayed around her decision to retire from professional practice, after forty years of practicing as a psychotherapist. The ideas presented in this work are complemented by those included in the work that follows: "King Lear and the challenges of retirement".

Key Words: Love, Hate, Retirement, Psychotherapist.

English Title: Love and Hate at the termination of a practice

\section{Cita bibliográfica / Reference citation:}

Buechler, S. (2021). Amor y odio en la terminación del ejercicio profesional. Clínica e Investigación Relacional, 15 (1): 33-45. [ISSN 1988-2939] [Recuperado de www.ceir.info ] DOI:

$10.21110 / 19882939.2021 .150103$

\footnotetext{
1 Trabajo leído en la reunión de la IFPS en Lisboa, Enero 2020. Las ideas expuestas en este trabajo se complementan con otro trabajo incluido en este mismo número: "El Rey Lear y los desafíos de la jubilación". Traducción castellana de Aleajdnro Ávila Espada.

2 Sandra Buechler, Ph.D. (New York), actualmente jubilada, ha sido Psicoanalista, Analista Didacta y Supervisora en el William Alanson White Institute y supervisora en el Programa postdoctoral y de Residentes del Columbia Presbyterian Hospital, así como en el Institute for Contemporary Psychotherapy. Entre sus obras: Valores de la Clínica: Emociones que guían el tratamiento psicoanalítico (2004); Marcando la diferencia en las vidas de los pacientes: Experiencia emocional en el ámbito terapéutico (2008); Permanezco ejerciendo: Las alegrías y angustias de una carrera clínica (2012); Comprendiendo y tratando pacientes en Psicoanálisis Clínico: Lecciones desde la Literatura (2015); Reflexiones psicoanalíticas. Formación y práctica (2018) y La aproximación psicoanalítica a los problemas del vivir (2019). Varias de ellas han sido traducidas al castellano y publicadas en la colección Pensamiento Relacional (Madrid: Ágora Relacional).
} 


\section{Anunciando la jubilación}

El 31 de mayo de 2019 dejé la consulta (como psicoterapeuta) que había comenzado en 1979. Algunos de mis primeros pacientes todavía estaban conmigo, unos 40 años después, mientras que otros habían llegado más recientemente, pero no menos de 3 años. Sin ser conscientes de ello, muchos habían esperado que envejeciéramos juntos. Así como habíamos entrado en la mediana edad aproximadamente al mismo tiempo, años antes, les parecía correcto que ahora enfrentaríamos las últimas etapas de la vida juntos. Mi decisión unilateral de retirarme conmocionó profundamente a algunos, confirmó lo que otros habían estado sospechando durante un tiempoy, para algunos, sospecho, fue un alivio, ya que ellos mismos se mostraron reacios a sacar a relucir el tema de la terminación.

El amor y el odio son solo dos de los sentimientos más intensos que se suscitaron. Después de contarles a ustedes un poco más sobre el proceso de anunciar mi retiro, me enfocaré en estas dos emociones a medida que aparecieron en la transferencia y la contratransferencia.

Mientras sopesaba la decisión de retirarme durante bastante tiempo, esperé hasta después de las vacaciones de verano de 2018 para anunciarla. Sentí que era un tema que no podía abordarse justo antes de la temporada de vacaciones de verano. Hubo algunos que supusieron que me estaría jubilando, ya que ya había dejado de enseñar en dos institutos, y confirmé su suposición cuando lo expresaron. Pero la mayoría no tenía idea hasta que se lo dije poco después de que retomáramos en septiembre de 2018. Pensé que nueve meses era un período de gestación práctico (y quizás también simbólico) para concebir un plan para la terminación.

Antes de continuar, me gustaría agradecer (su ayuda) a Donna Orange. Ella compartió generosamente sus propias experiencias de esta etapa de una carrera profesional, y tuvo una comprensión más compasiva y sabia de cómo era para mí vivirla.

\section{Amor y Odio}

En este trabajo, me baso en mi escrito anterior (Buechler, 2019) sobre la naturaleza del amor. En este trabajo anterior sugerí que la capacidad de amar y la capacidad de soportar la soledad son gemelos, ambas nacidas de la experiencia de la parentalidad sintonizada. La figura parental suficientemente buena fomenta el desarrollo en el niño de objetos internalizados positivos, lo que le permite desarrollar la constancia del objeto. Brevemente, aquí está la esencia de lo que dije.

Al revisar tanto a Rilke como a Winnicott, me parece que la persona afortunada, nacida con un cuidado suficientemente bueno, será (en algún momento) capaz de resistir los impulsos de fusionarse o huir para sentirse segura. Será capaz de soportar difíciles pasajes de soledad y 
relación. Los momentos difíciles inherentes tanto a la soledad como a la conexión no tendrán el poder de persuadirla de que el mundo interior o exterior es insoportablemente peligroso. En otras palabras, tanto la difícil soledad como la dificultad para relacionarse serán desafíos no traumáticos. Este afortunado niño / adulto se sentirá capaz de sortear estos desafíos sin recurrir a medidas drásticas, como fusionarse con el otro o huir.

Pienso en esta persona afortunada como capaz de constancia objetal. La estabilidad del objeto interno le permite capear las fluctuaciones y ausencias del otro (externo). Otra forma de decir esto es que el objeto interior intacto llena y centra el Self. Por lo tanto, la persona afortunada puede seguir amando, a pesar de los cambios en el amado, y puede seguir sintiéndose emocionalmente arraigado durante los períodos de soledad (Buechler, 2019, págs. 18-19).

Una expresión más poética de la capacidad del amor para la constancia del objeto se puede encontrar en el gran soneto de Shakespeare, "No admita yo impedimento al enlace de dos

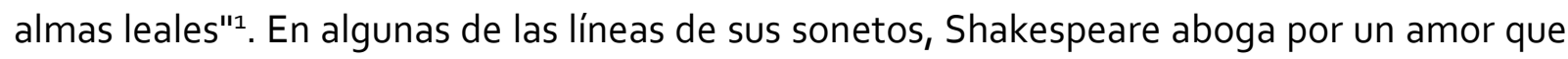
resiste todos los cambios.

, pues el amor no es amor

si se altera cuando alteración encuentra,

o si se curva cuando la mudanza lo muda.

¡Oh, no! El amor es marca siempre fija

que a la tempestad se muestra y no se estremece;

De los barcos perdidos es la estrella que guía, cuyo secreto, aun imitando su altura, se ignora.

El amor no es juguete del tiempo, aunque el soplo

de su guadaña sientan mejillas y labios, antes rosa;

Y no se altera por el paso de las breves horas,

sino que perdura hasta la frontera de los días.

Si esto es error y quedara en mí probado,

ni nunca he escrito, ni hombre nunca ha amado.

(Shakespeare, 1996, p. 332)

Shakespeare nos dice lo que puede resistir el verdadero amor. Ni el cambio en el amado, ni los trastornos de la vida, ni el tiempo, ni el destino implacable lo altera. Una forma de entender esto es que al no mirar fuera de nosotros mismos para completar el Self, somos capaces de amar sin importar lo que suceda y sentir que la plenitud es posible incluso en soledad (Buechler, 2019, p.19). 
¿Pudimos mis pacientes y yo amarnos durante la fase de terminación? Mi lenguaje para esto sería hacer la pregunta, ¿fueron capaces de amarme de todos modos?

En mi idioma, uno de los mayores desafíos de la vida es "amar la vida de todos modos", a pesar de su inevitable dolor. ¿Podemos lograr la "constancia del objeto" hacia la vida misma y/ o la humanidad misma, sin importar cómo se "altere"? Para mí, mi relación con la vida misma, así como todas mis otras relaciones internas y externas, píden esto. Para todos nosotros, ¿cómo podemos amarnos (a nosotros mismos, a los demás, a la vida) de todos modos? ¿Y cómo se puede incorporar esta parte de nuestra experiencia de ser humano a nuestro trabajo como analistas? Me viene a la mente una analogía con el Edipo. Para mí, el significado esencial de la saga de Edipo se centra en el tema del deseo. ¿Qué pasa cuando queremos el otro ${ }^{2}$ que no podemos tener? ¿Arrepentimiento exquisito, vergüenza eterna, castigo sin fin? Todos queremos lo que no podemos tener. Todos soportamos profundas decepciones. Sin embargo, necesitamos decir "si" a la vida, con todas sus humillaciones, indignidades y dolores penetrantes. Si podemos perdonar a la vida, tal vez nuestro dolor se convierta en dolor y no en dolor mezclado con rabia, culpa y arrepentimiento. Todo lo que la vida da, también lo quita. ¿Podemos perdonar a la vida por eso? ¿Puede nuestro amor a la vida mirar las tempestades sin ser sacudidas? ¿Podemos amarla de todos modos? Para mí, nada es más difícil, o más importante, que esta prueba definitiva de constancia del objeto (Buechler, 2019, p.19).

Ahora diría que el reto en el proceso de mi jubilación fue si podía seguir siendo yo misma, para mis pacientes (y también, internamente, para mí). ¿Podría seguir siendo quien era antes de decidir retirarme? Algunos de los pacientes por los que seguí siendo yo me habían amado y podían seguir haciéndolo. Otros no me vieron alterada significativamente por esta decisión, pero nunca me habían amado. Algunos habían sentido amor por mí antes, pero ya no podían sentirlo, ya que su experiencia de mí había cambiado tan radicalmente que sentían que tenían que revisar todas sus creencias sobre quién soy. $Y$ hubo algunos que no sintieron amor, sino odio o, al menos, una mezcla de sentimientos que incluía el odio. Por supuesto, para cada paciente lo que se evocó fue diferente. Por ejemplo, transferencialmente, algunos habían perdido a sus padres $u$ otras personas importantes, y evocaron estas experiencias anteriores. Mis propias pérdidas entraron en juego en algunas sesiones más que en otras. Cada pérdida es su propio país, con un terreno que solo se puede conocer atravesándolo.

Para algunos de mis pacientes, mi decisión de jubilarme puso en duda todo lo que pensaban que sabían sobre mí. ¿Quién era yo para poder tomar esta decisión unilateral? ¿Qué éramos, en realidad, el uno para el otro? ¿Qué significa sobre la relación que pensaban que teníamos, 
que yo podría terminarla? ¿Eso cancela años de conocimientos, junto con la fe en nuestra reciprocidad?

No eran solo los pacientes los que se preguntaban qué significaba esta decisión sobre quién soy realmente. Pasé muchas horas reflexionando sobre mí misma. Después de todo, durante gran parte de mi carrera escribí sobre mantener vivo el propósito terapéutico. El título de uno de mis libros es Permanezco ejerciendo. ¿Me estaba engañando a mí misma y / o a los demás cuando escribí sobre las gratificaciones que encontré en el trabajo? ¿Significaba esto en última instancia que, en primer lugar, no había amado realmente el psicoanálisis, ni a mis pacientes?

Como sin duda pueden imaginar, algunas sesiones de tratamiento se sintieron llenas de una emoción más cercana al odio que al amor. Permítanme detenerme para ver cómo se ha entendido el odio, primero por Erich Fromm. En el artículo de 1939 de Fromm, "Egoísmo y amor propio"3 define el odio racional reactivo como una respuesta biológicamente condicionada a amenazas reales o imaginarias al bienestar de uno. Fromm lo distinguió del tipo de odio que es una cualidad permanente del carácter de la persona. Así, un tipo de odio, el odio reactivo, es una respuesta transitoria a una amenaza y no un motivo destructivo profundamente arraigado. Me parece significativo que la amenaza pueda ser imaginaria. Pero lo más relevante aquí es la idea de que Fromm vincula el odio reactivo con la necesidad de bienestar de la persona, y no con un instinto de muerte innato.

Man for Himself: An Inquiry into the Psychology of Ethics se publicó en 1947 4 . Una vez más, (p.216) Fromm distinguió dos formas de odio, racional o reactivo, e irracional, odio "condicionado por el carácter". En este libro, Fromm elaboró el concepto de odio reactivo, definiéndolo como "la reacción de una persona a una amenaza a la libertad, la vida o las ideas propias o de otra persona. Su premisa es el respeto por la vida. El odio racional tiene una función biológica importante: es el equivalente afectivo de la acción al servicio de la protección de la vida; nace como reacción a amenazas vitales y deja de existir cuando la amenaza ha sido eliminada; no es lo opuesto sino el concomitante de la lucha por la vida" (cursiva en el original).

Otro concepto de Fromm es relevante, en su libro de 1964 sobre el corazón del hombre. Aquí Fromm escribió sobre la "violencia vengativa" que surge de una herida que ha ocurrido y tiene como motivo una reparación mágica de la herida. Dado que no está al servicio de obtener algo necesario para la supervivencia, su motivación tiene un elemento destructivo. Para Fromm, una emoción aún más patológica es la "violencia compensatoria", o la violencia como sustituto de la actividad productiva, que puede resultar de una fuerte decepción, la destrucción de la fe o la desesperación. 
Este concepto me vino a la mente en algunos de mis momentos más oscuros después de anunciar mi retiro. Escuché a los pacientes expresar su sensación de sentirse heridos y con decepción aguda. Algunos se negaron a considerar siquiera tomar un nombre para una posible derivación en el futuro, afirmando que nunca volverán a recibir otro tratamiento bajo ninguna circunstancia. En algunos intercambios, sentí que el paciente estaba, en efecto, rompiendo nuestro trabajo, diciendo que no tenía ninguna utilidad, cancelando su significado en represalia por mi retiro. No sé si Fromm llamaría a esto odio racional, vengativo o compensatorio, pero me pareció odio.

Sullivan (1956, p.104) Ilamó al odio "... el horrible aborto involuntario de la intimidad humana, mezclado con una lucha casi omnipotente sobre quién lastimará más al otro compañero". No diría que sentí odio, pero sí sentí una especie de atracción hacia las represalias. Si bien podía justificar la "interpretación" del comportamiento de los pacientes, sabía que mis propios motivos no eran solo terapéuticos y no se trataba solo de aclarar lo que estaba sucediendo, aunque esto era parte de lo que intenté hacer, pero había un aspecto de retaliación en ellos también.

Mi comprensión del odio también se basa en el trabajo del teórico de la emoción, Cal Izard (1972, p.113) con quien colaboré en la década de 1970. En su marco teórico, hay emociones fundamentales, como el miedo, la ira, la alegría, la vergüenza y otras, y las emociones complejas, como la depresión y la ansiedad. Izard vería el odio como "un sentimiento compuesto de ira, miedo y disgusto". El aspecto de la ira de esta emoción compleja es una respuesta a un obstáculo percibido.

Fromm, Sullivan e Izard me parece que articulan conceptos relevantes para algunos de mis sentimientos y los de mis pacientes, a medida que avanzaba el proceso de terminación. En el sentido de Izard, mis pacientes y yo éramos obstáculos para los deseos del otro, generando así fácilmente ira, si no odio. Lo que ellos querían y lo que yo quería estaban en desacuerdo, al menos a veces. Para ser más específica, hubo momentos, para mí, en los que quería que estuvieran bien con mi jubilación, pero, para algunos de ellos, esto se habría sentido como colaborar demasiado en contra de sus propios intereses. Así que el enojo mutuo como obstáculo era bastante comprensible. Pero, entonces, ¿el sentimiento se parecía más al odio que a la ira? Y si es así, ¿por qué?

Afortunadamente, puedo decir que la mayor parte del tiempo no me sentí odiada ni odiando. Quizás esto agudice los momentos en que sentí odio en el despacho. Creo que esto ocurrió cuando uno o ambos sentimos que el proceso de separación podría ser más de lo que podíamos soportar. El dolor amenazaba con abrumarlos a ellos, a mí o a los dos. En estos 
momentos, ciertamente puedo estar de acuerdo con el sentido de odio racional de Fromm como reacción a la amenaza.

La idea de alguna forma de ira como una forma de escapar del dolor abrumador recibió una expresión poética de Shakespeare en El rey Lear cuando el viejo rey comienza a sentir la amenaza de la desintegración. Es entonces cuando ora pidiendo ira / rabia / odio para evitar que se disuelva.

...denme la noble indignación

y no permitan que femeniles armas, gotas de agua no más,

amancillen mi rostro de hombre... No, feroces arpías,

sobre las dos ha de caer mi castigo

de modo tal que el mundo todo... ¡Tales cosas haré...!

No sé cuáles serán, pero serán

espanto de la tierra. ¿Creen que vaya a llorar?

¡No, no lloro!

¡Razón tendría el llanto,

pero antes que llorar

romperé mi corazón en mil pedazos!

¡Oh, mi bufón; me volveré loco!

(Acto II, Escena IV, 274-284)

En una contribución anterior (1995) sugerí que el odio es más probable que centre y fortalezca los recursos individuales en situaciones que nos amenazan con profundo dolor. Odiamos la destrucción de nuestro medio ambiente, imaginando y, en último caso, sintiendo ya la pérdida. Odiamos la intolerancia porque esta destruye la humanidad tanto de su perpetrador como de su víctima. Odiamos el azote nazi por nuestra pena ante la devastación que causó. Odiamos para permanecer unidos ante el dolor extremo. En el contexto de la pena suprema, el odio puede suministrar fortaleza al sensible.

\section{Fases de la terminación de mi ejercicio profesional}

Inicialmente, no creo que mi jubilación se sintiera real para mí o para mis pacientes. Era un concepto, desprovisto de significado concreto. Entonces, el lunes 3 de junio de 2019 todavía fue un shock, a pesar de que todos sabíamos que vendría durante muchos meses. Sherman Alexie dio expresión poética a poderosas defensas contra la pérdida consciente en su poema, "El dolor nos llama a las cosas de este mundo" (2009). 
Los ojos se abren a un teléfono azul

En el baño de este hotel de cinco estrellas.

¿Me pregunto a quién debo llamar? Un plomero, ¿Proctólogo, urólogo o sacerdote?

Quien está entre nosotros y más merece ¿La primera llamada? Elijo a mi padre porque

Está asombrado por los teléfonos del baño.

Marco a casa. Responde mi madre. "Oye, mamá"

Yo digo: "¿Puedo hablar con papá?" Ella jadea

Y luego recuerdo que mi padre

Ha estado muerto durante casi un año. "Mierda, mamá"

Yo digo. "Olvidé que está muerto. Lo siento-

¿Cómo lo olvidé? "Está bien", dice ella.

"Le preparé una taza de café instantáneo

Esta mañana y lo dejé sobre la mesa-

Como lo he hecho durante, qué, veintisiete años ...

Y no me di cuenta de mi error

Hasta esta tarde ". Mi madre se ríe

A los ángeles que esperan que hagamos una pausa

Durante los días más ordinarios

Y cantamos nuestras alabanzas al olvido

Antes de que golpeen nuestras almas con sus alas frías.

Esos ángeles nos agobian y nos desequilibran.

Esos jodidos ángeles nos montan a cuestas.

Esos ángeles cayendo para siempre, nos atrapan

Y arrástranos, presa y rezando, al polvo.

(Seiden, 2016, págs. 1-2).

Mi esfuerzo consciente fue hacerlo sentir real, por etapas, para mí y para los demás. Dejé de enseñar en institutos, fijé una fecha para jubilarme, lo comuniqué al propietario del despacho, creé un sistema para asegurarme de que se lo decía a todos, desarrollé una lista de referencias y mencioné la terminación periódicamente cuando los pacientes no lo hacían. Pero, por 
supuesto, nada de esto impidió que fuera un shock, y movilizara defensas, esos malditos ángeles que cantan nuestras alabanzas al olvido.

Hubo un período inicial en el que algunos pacientes no querían, o tal vez no podían hablar de ello, mientras que otros no hablaban de nada más. Luché porque no sabía cuándo mencionarlo. Por ejemplo, a menudo no estaba segura de si se refería a mi jubilación en el sueño de un paciente, y si debería interpretar esto. Quizás, de manera contratransferencial, temía la vergüenza de parecer pensar que soy de importancia central en la vida del paciente. Creo que el peligro a veces se sentía mayor según el género y la edad del paciente en comparación con el mío. Creo que además de mis problemas personales sobre este tema, también hay una contribución cultural a la vergüenza de las mujeres mayores por temor a que parezca que exageramos cuánto nos quiere un hombre más joven.

A medida que pasaba el tiempo, hubo algunos cambios significativos en los sentimientos expresados por muchos pacientes. La terminación se hizo más real a medida que se acercaba. Sus consecuencias desarrollaron especificidad, por ejemplo, que yo no estaría allí para celebrar eventos importantes en la vida de los pacientes, o que sus rutinas en las sesiones no ocurrirían, ellos extrañarian la cafetería del vecindario, así como a mí, y ¿Cómo pasarían los martes? Muchos se entristecieron.

Poco a poco, para muchos, proliferaron las preguntas. ¿Puedo enviarte un correo electrónico? ¿Llamar? ¿Almorzar? ¿Me contarás más sobre tu decisión de hacer esto? ¿Cómo está tu salud? ¿Me dejarás saber cómo estás de vez en cuando? ¿Cómo sabré lo que te pasa y cómo sabrás lo que me pasa a mí? ¿Qué estarás haciendo?

A medida que proliferaban las preguntas, también lo hacían los sentimientos relacionados con la ira. Por supuesto, si mis respuestas hubieran sido diferentes, sin duda los sentimientos que engendraron podrían haber sido diferentes o, quizás, menos intensos. Pero mi propio sentimiento, además de la necesidad de encontrar un camino a seguir que se sintiera viable, era que no quería prometer nada que no estaba segura de poder cumplir. ¿Qué pasa si desarrollo una enfermedad grave después de jubilarme? ¿Realmente querré mantenerme en contacto con ellos y discutir mi enfermedad con mis antiguos pacientes? Por otro lado, ¿no estaría en contra del espíritu del trabajo que hicimos que enviase ocasionalmente un mensaje superficial de que "Estoy bien" sin importar lo que realmente me estuviese sucediendo?

Algunos pacientes aceptaron esta explicación fácilmente. Otros ni siquiera mencionaron la cuestión del contacto continuo. Para muchos colegas, no surgió de manera puntual, quizás en parte porque estaremos en contacto a través de nuestros círculos profesionales. Pero algunos plantearon fuertes objeciones, incluso diciendo que no tener nunca más contacto, dado todo lo que habíamos pasado juntos, era simplemente impensable. Tenía que estar de acuerdo con 
esto. Para mí también era impensable. Pero también lo era cualquier otro enfoque que pudiera imaginar.

Esta fue la situación que engendró emociones más cercanas al odio, tanto en mí como en algunos pacientes. Creo que algunos sintieron que no solo les estaba cerrando una puerta en la cara, sino que les estaba quitando el recuerdo de nuestra relación como pensaban que la conocían. Efectivamente los estaba borrando y borrándonos a nosotros. Por mi parte, me sentí en un aprieto, expuesto, culpable, avergonzado de no poder encontrar un mejor enfoque y triste por las pérdidas que ambos estábamos experimentando. Para volver a la comprensión del odio de Fromm, estas sesiones a veces se sentían como una amenaza para mi estabilidad. Tenía que seguir adelante, pero no sabía si podría. Por momentos podía imaginar que sería un alivio simplemente alejarme del proceso. Pero no lo hice, y casi todos mis pacientes se quedaron hasta que terminé mi práctica.

En retrospectiva, creo que retirarme, voluntariamente, cuando no parecía muy enferma, desmentía fantasías sobre la relación terapéutica que no eran del todo conscientes para ninguno de los participantes. Es muy interesante para mí que, en mi libro de 2012, Permanezco ejerciendo, escribí una sección extensa sobre las fantasías que no son confirmadas por la mera existencia del encuadre. Mirando hacia atrás, ahora puedo aplicar algunas de las ideas en esa sección a la interacción emocional en la jubilación que es, en cierto sentido, la máxima expresión del encuadre. Esto es algo de lo que escribí entonces, sobre el encuadre en sí. Mientras leo algunos de estos pensamientos anteriores sobre la existencia del encuadre, les pido que consideren cómo podrían aplicarse a la situación cuando el analista se retira. Primero, permítanme mencionar que el capítulo de Permanezco ejerciendo que trata sobre el encuadre se titula "Las Tragedias Ordinarias de una Vida Analítica". Ahora diría que jubilarse puede parecer la máxima tragedia ordinaria.

\section{Pérdida de la fe en la armonía mágica}

"El tratamiento demuestra y confirma que no podemos esperar una armonía mágica entre los demás y nosotros mismos. Por la existencia misma del encuadre, niega la esperanza de que el analista aparezca justo en el momento en que más se lo necesite. De manera similar, para el analista, el encuadre confirma que las reglas son necesarias para garantizar que el paciente asista a las sesiones, pague los honorarios $y$, en general, se abstenga de los comportamientos que prohíbe. En otras palabras, la magia de dos personas en perfecta sincronía, que automáticamente conocen y satisfacen las necesidades del otro, no es de 
esperar. Para la mayoría de las personas esto no es una novedad. Pero no creo que eso signifique que no se experimenta como una pérdida $y$, a veces, una pérdida traumática.

De manera similar, el encuadre confirma que la magia de ser perfectamente entendido será algo poco común, si es que alguna vez ocurre. Como siempre, estoy usando la palabra "encuadre" en un sentido Levensoniano para significar el establecimiento de lo que se puede y no se puede esperar del tratamiento "(Buechler, 2012, p. 170).

"Esperamos que en la infancia podamos sentirnos con derecho a que se satisfagan las necesidades básicas. Si necesitamos mucha atención, hay una manera de hacerlo (al menos en circunstancias familiares relativamente buenas). Creo que para muchos, el encuadre revive el momento de nuestras vidas en el que reconocimos conscientemente por primera vez que es posible que no recibamos atención cuando más la necesitemos. Un adulto tiene que poder soportar esto. Algo más, o alguien más, puede ser la prioridad. Para algunos, el encuadre cristaliza este aspecto de la vida adulta. En cierto sentido, ambos participantes tenemos que aceptar, como todos hacemos en algún momento, que a veces no es nuestro turno. Es de otra persona. No importa cuánto necesitemos o deseemos que sea nuestro turno, todavía es el de otra persona. En la primera infancia no se espera que comprendamos el concepto de turnarse. Pero en algún momento esto cambia. Para muchos, creo, el encuadre es un recordatorio de ese cambio, una reiteración del mismo y una oportunidad, en cierto sentido, de revivirlo y reelaborarlo. ¿Cómo soportamos saber que puede que no sea nuestro turno en el momento de nuestra necesidad más intensa?" (Buechler, 2012, p.171).

Gran parte del resto de este capítulo de 2012 se ocupó de fantasías más específicas desmentidas por la existencia del encuadre: la fantasía del alma gemela perfecta, la fantasía de prescindir de la necesidad de interés propio, la fantasía de las palabras siendo innecesarias, la fantasía de tener todas las necesidades cubiertas por una sola persona, y la fantasía de un perfecto acuerdo. La decepción de estas fantasías puede cristalizarse al terminar, cuando la indisponibilidad se vuelve palpable y permanente.

Terminé el capítulo de 2012 con esta esperanza para cuando me jubilara.

"Para mí, el aspecto de la terminación de un tratamiento que es más difícil de realizar es el empobrecimiento de mi propia experiencia personal. Es mucho más fácil (aunque puede ser doloroso) comprender la pérdida del paciente. Lo más difícil es comprender que debido a este final, yo misma estoy disminuida. Algunos de mis yoes se han ido. Las personas en las que me estaba convirtiendo puede que nunca existan. Esto puede ser extremadamente difícil de comprender, y mucho menos de aceptar. Volviendo al tema de Maisy ${ }^{5}$, la paciente que 
describí en la apertura de este capítulo, quiero expresar que para cuando me retire de la práctica, espero haber aprendido más formas de aferrarme a mi Maisy " (2012, p. 178).

Todavía estoy trabajando en este objetivo. Pero me siento más clara, ahora, sobre las dolorosas decepciones y pérdidas que pueden ser inevitables, pero que aún pueden ser impactantes en el transcurso de todas las terminaciones, y, quizás especialmente, cuando el analista elige retirarse. Quizás no debería sorprendernos que algunos reaccionen inicialmente a estas pérdidas con odio, lo que puede ser una forma de defenderse de un mar de dolor.

Me alegra poder decir que, en las últimas semanas de mi práctica profesional, la balanza se inclinó en una dirección más positiva. Con algunos, llamaría al sentimiento entre nosotros una forma de amor. Con otros, se sintió más como resignación o voluntad de aceptar la situación y el reconocimiento de que nuestras necesidades eran diferentes. Pero la mayoría sentía que se preocupaba por mí, así como por ellos mismos. Siempre me ha gustado la definición de amor de H.S. Sullivan. Aunque engorrosa, como la mayor parte de su lenguaje, en mi opinión, capturó algo vital. Dijo que el amor existe cuando (1940, págs. 42-43) "... la satisfacción o la seguridad de otra persona se vuelve tan importante para uno como lo es la propia satisfacción o seguridad, entonces existe el estado de amor". De manera similar, en su libro tremendamente popular, El arte de amar (1956, p. 24), Erich Fromm definió el amor como la "preocupación activa por la vida y el crecimiento de aquello que amamos". Según estos estándares, diría que la mayoría de mis pacientes y yo pudimos amarnos. Mi propio objetivo era vivir la terminación lo mejor que podía, lo que veo como un objetivo mucho más realista que intentar que salga de alguna manera en particular. En lo que a mí respecta, puedo decir que el objetivo de "vivirlo lo mejor que pueda" se aplica a los momentos más importantes de mi vida, como clínico y, en términos más generales, como ser humano.

\section{REFERENCIAS}

Buechler, S. (2012). Still Practicing: The Heartaches and Joys of a Clinical Career. New York: Routledge.

Buechler, S. (2015). Marcando la diferencia en las vidas de los pacientes: Experiencia emocional en el ámbito terapéutico. Madrid: Ágora Relacional [Original de 2008].

Buechler, S. (2019). Psychoanalytic Approaches to Problems in Living: Addressing Life's Challenges in Clinical Practice. New York: Routledge.

Fromm, E. (1939). Selfishness and self love. In: Psychiatry, 2, no. 3, pp. 507-524.

Fromm, E. (1947). Man For Himself. New York: Rinehart.

Fromm, E. (1956). The Art of Loving. New York: Harper \& Row. 
Fromm, E. (1964). The Heart of Man: Its Genius for Good and Evil. New York: Harper \& Row.

Izard, C. (1972). Patterns of Emotion. New York: Academic Press.

Seiden, H. M. (2016). The Motive For Metaphor: Brief Essays on Poetry and Psychoanalysis. London: Karnac.

Shakespeare, W. (1972). King Lear In: The Arden Edition of the Works of William Shakespeare. London: Methuen.

Sullivan, H.S. (1940). Conceptions of Modern Psychiatry. New York: Norton.

Sullivan, H.S. (1956). Clinical Studies in Psychiatry. New York: Norton.

Original recibido con fecha: 1/4/2020 Revisado: 28/3/2021 Aceptado: 30/03/2021

NOTAS:

${ }^{1} \mathrm{~N}$. de T.: Soneto CXVI (116)

${ }^{2} \mathrm{~N}$. de T.: La autora usa un juego expresivo (m)other que reúne a la madre y al otro.

3 "Selfishness and self-love" Psychiatry, 2, no. 3: 507-524,

${ }^{4}$ Nueva York: Rinehart \& Co.

${ }^{5}$ N. de T.: La autora se refiere a quien ha denominado Maisy en ese capítulo (S. Buechler, 2012, Cap. 8) como una hermosa y expansiva adolescente intensamente emocional, concierto sobrepeso, y risa contagiosa que oscilaba entre expresiones duras y joviales. Menciona que su presencia dejaba huella, también olorosa de su escasa higiene, en el despacho de Sandra Buechler, quien además se sentía (aún más) empequeñecida en su presencia, anémica frente a su "vitalidad". La huella de Maisy, en las experiencias de Sandra Buechler, es imborrable. Es una historia que permanecerá "inacabada". 